\title{
INFRAESTRUTURA ESCOLAR: INTERFACE ENTRE A BIBLIOTECA E AS POSSIBILIDADES DE APRENDIZAGEM DOS ALUNOS
}

\author{
SCHOOL INFRASTRUCTURE: INTERFACE BETWEEN THE
} LIBRARY AND STUDENTS'LEARNING POSSIBILITIES

\section{LA INFRAESTRUCTURA ESCOLAR: INTERFAZ ENTRE LA BIBLIOTECA Y LAS POSIBILIDADES DE APRENDIZAJE DE LOS ALUMNOS}

\author{
Paulo Sérgio Garcia* \\ Universidade Municipal de São Caetano do Sul, Professor no Departamento de Educação; \\ Coordenador do Observatório da Educação do Grande ABC Paulista; Universidade de São \\ Paulo, Pesquisador da Faculdade de Educação (Formação de Professores, Neurociência \\ e Educação Escolar); Universidade Federal de Santa Maria, Pesquisador do Grupo \\ Interinstitucional Desempenho Escolar e Inclusão Acadêmica
}

Resumo: Com este estudo objetivou-se investigar como ocorre a interface entre a biblioteca e as possibilidades de aprendizagem dos alunos. Um estudo de caso foi utilizado para coletar dados junto às escolas municipais de Ensino Fundamental I da região do Grande $\mathrm{ABC}$, nas quais os alunos apresentaram alto desempenho na competência de leitura e interpretação de textos na Prova Brasil (2011). Os resultados mostraram que as escolas organizavam e utilizavam diferentes ações educativas e projetos pedagógicos, organizados pelos professores e pela gestão escolar. Mais de 30 projetos foram identificados e agrupados. Seus objetivos se associavam ao desenvolvimento da leitura e à ampliação do tempo de aprendizagem, entre outros. Compreender a organização das ações educativas e dos projetos pedagógicos e o sentido destes para as escolas pode contribuir trazendo indicações aos diretores no intuito de auxiliá-los a melhorar o desempenho dos alunos em leitura.

Palavras-chave: Infraestrutura. Biblioteca. Ensino Fundamental I. Projetos pedagógicos.

* Pós-Doutor e Doutor em Educação pela Faculdade de Educação da Universidade de São Paulo. 
Abstract: In this study it was aimed to investigate how the connection between the library and student learning opportunities is established. A case study was used to collect data from the municipal elementary schools (Ensino Fundamental I) in the Great $A B C$ region, in which the students presented high performance in reading skills and text comprehension in Brazilian Exam (Prova Brazil) (2011). Results showed that schools organized and used different educational and pedagogical projects, organized by teachers and school management. More than 30 projects have been identified and grouped. Their objectives were associated with the development of reading and the expansion of learning time. Understanding the organization of educational and pedagogical projects and their meaning to schools can contribute bringing directions to principals in order to assist them to improve students' reading performance.

Keywords: School infrastructure. Library. Elementary School. Pedagogical projects.

Resumen: Este estudio tiene como objetivo investigar cómo es la interfaz entre la biblioteca y las oportunidades de aprendizaje del estudiante. Un estudio de caso se utilizó para recopilar datos de las Escuelas Primarias Municipales I de la región del Gran ABC, que los estudiantes presentan un alto rendimiento en las habilidades de lectura y la interpretación de los textos en la Prueba de Brasil (2011). Los resultados mostraron que la escuela organiza y utiliza diferentes proyectos educativos y pedagógicos, organizados por los maestros y la gestión escolar. Han sido identificados y agrupados más de 30 proyectos. Sus objetivos se asociaron con el desarrollo de la lectura y la expansión de tiempo de aprendizaje, entre otros. Comprender el significado de la organización de las actividades y proyectos educativos ayuda a los directores en la organización escolar para mejorar el rendimiento de la lectura en los estudiantes.

Palabras clave: Infraestructura. Biblioteca. Proyectos educativos Escuela Primaria I.

\section{INTRODUÇÃO}

Estudos brasileiros já mostraram que a maior parte do desempenho acadêmico dos estudantes, cerca de dois terços, tem associação direta com a família, sobretudo o nível socioeconômico e a escolaridade dos pais (ALBERNAZ; FERREIRA; FRANCO, 2002; FELÍCIO; FERNANDES, 2005). A outra parte do rendimento dos jovens apresenta relações com as características escolares e é denominada efeito escola (FLETCHER, 1997; FERRÃO; BELTRÃO; SANTOS, 2002). 
Entre os vários fatores relacionados às características da escola que influenciam a aprendizagem e o desempenho do jovem está a infraestrutura escolar (IE). O termo IE tem sido utilizado, entre outras coisas, como sinônimo de condições materiais, condições físicas, recursos físicos, recursos pedagógicos, dependências, equipamentos, infraestrutura física e infraestrutura escolar. No entanto, a infraestrutura escolar pode ser caracterizada "[...] como um sistema de elementos estruturais, inter-relacionados, que inclui as instalações, os equipamentos e os serviços necessários para garantir o funcionamento da escola e impulsionar a aprendizagem do aluno." (GARCIA, 2014, p. 155). Trata-se de uma variável que tem impacto sobre o desempenho escolar dos alunos, o que não acontece em países desenvolvidos, pois as escolas contam, praticamente, com os mesmos recursos para o funcionamento. Dependendo da localização da escola, rural ou urbana, da esfera (municipal, estadual, particular), ou dos investimentos realizados, há grande diferença, no Brasil, em relação à infraestrutura das unidades escolares.

Os pesquisadores Castro e Fletcher (1986) realizaram um estudo sobre a IE das escolas brasileiras, constatando a precária situação das instalações físicas das instituições e a pouca quantidade de equipamentos e materiais disponíveis para os professores para a realização de atividades pedagógicas. Realizado na década de 1980, com pioneirismo, esse estudo foi um dos primeiros a revelar a importância, no contexto brasileiro, da IE em relação ao desempenho do jovem. No contexto brasileiro e da América Latina, a IE é fundamental para o desempenho dos alunos, mesmo quando os resultados são controlados pelo nível socioeconômico deles (FRANCO; BONAMINO, 2005).

Estudo realizado na região do Grande $\mathrm{ABC}$ revelou a infraestrutura das escolas de Ensino Fundamental I e II no sentido de, inicialmente, compreender tal cenário e, posteriormente, favorecer a reflexão sobre possíveis alternativas para a organização (ou reformas) das redes, do sistema educacional ou das escolas, considerando que a infraestrutura impacta positivamente o rendimento dos alunos (GARCIA et al., 2014). Essa pesquisa analisou também a disponibilidade das bibliotecas nas escolas para o desenvolvimento da capacidade de leitura dos jovens.

Casassus (2002) revelou que os materiais didáticos, em geral, influenciaram a aprendizagem em linguagem, sobretudo a disponibilidade de livros na biblioteca escolar. No mesmo sentido, Biondi e Felício (2007) e Felício (2008) mostraram que a biblioteca apresenta resultados estatisticamente significativos e positivos no desempenho dos alunos. Evidentemente que o efeito biblioteca não ocorre somente porque a escola dispõe de tal espaço com livros adequados. A presença desse local não 
avaliza nem a aprendizagem nem o desempenho dos jovens. Não há uma relação, uma interface direta entre a biblioteca e seus recursos e a aprendizagem e o rendimento dos alunos, é preciso que projetos pedagógicos e iniciativas educativas sejam criadas e desenvolvidas para que essa interligação ocorra. Nesse sentido, neste estudo teve-se o objetivo de investigar e analisar, nas escolas municipais de Ensino Fundamental I da região do $\mathrm{ABC}$ paulista, como ocorre essa interface entre a biblioteca e as possibilidades de aprendizagem dos alunos. Pretendeu-se, com esta pesquisa, contribuir com a ampliação da compreensão do efeito biblioteca no desempenho do aluno, já que a grande maioria dos estudos que revelaram tal fenômeno foi realizada por meio de análises quantitativas, que não permitem análises mais pormenorizadas e detalhadas.

\section{INFRAESTRUTURA ESCOLAR}

Os fatores que influenciam a aprendizagem e o desempenho dos alunos nas escolas de educação básica têm sido analisados em diferentes partes do mundo, incluindo o Brasil. Os principais fatores se relacionam à família: nível socioeconômico (NSE) e formação dos pais. Tais premissas foram mostradas em estudos realizados nos Estados Unidos (COLEMAN, 1966), na França (SAUVY; GIRARD, 1965; CENTRE DE RECHERCHE DE L'EDUCACION SPECIALISEE ET TE L'ADAPTATION SOLAIRE, 1978) e também na Inglaterra (DOUGLAS; ROSS; SIMPSON, 1968).

Pesquisas internacionais mais atuais (ORGANIZAÇÃO PARA A COOPERAÇÃO E DESENVOLVIMENTO ECONÔMICO, 2011), realizadas com a utilização dos dados do Programa Internacional de Avaliação de Estudantes (Pisa), permitiram, além de compreender a universalidade de tal fenômeno, entender que a condição social, econômica e cultural dos pais explica em grande parte os conhecimentos, as competências e as habilidades obtidas pelas crianças e jovens. Tal situação significa que alunos naturais de famílias menos favorecidas economicamente apresentam em média desempenhos escolares menos satisfatórios e que "[...] o sucesso escolar é, portanto, ainda hoje, o campo de um determinismo social gerador de desigualdades, o que autoriza a concluir que não existe em nenhum lugar uma escola plenamente justa e eficaz.” (CRAHAY; BAYE, 2013, p. 878).

Além desses fatores relacionados às famílias, existem outros associados às características da escola que também influenciam o rendimento dos jovens brasileiros. Sammons, Hillman e Mortimore (1995) realizaram um estudo no qual identificaram 11 fatores interdependentes atrelados às características das escolas eficazes: liderança profissional, objetivos e visões compartilhadas, ambiente de 
aprendizagem, concentração no ensino e na aprendizagem, ensino e objetivos claros, altas expectativas, incentivo positivo, monitoramento do progresso do aluno, direitos e responsabilidades do jovem, parceria casa-escola e uma organização orientada à aprendizagem. Em outra pesquisa, Lee, Bryk e Smith (1993) revisaram a literatura sobre a organização nas escolas que apresentaram altos resultados. Os autores sugeriram um modelo conceitual no qual fatores externos e internos atuavam juntos. Casassus (2002), na América Latina, revelou que o clima favorável à aprendizagem se constitui em um dos aspectos mais importantes para o desempenho dos alunos. Outros pesquisadores, como Mella et al. (2002) e Raczynski e Muñoz (2007), realizaram estudos mostrando alguns fatores que foram determinantes para que escolas pobres do Chile obtivessem desempenhos elevados nas avaliações nacionais: respeito às ideias e apreciações dos professores, apoio individual ao aluno, baixa rotatividade do corpo docente, gestão centrada no pedagógico, trabalho pedagógico fora da sala de aula, altas expectativas de docentes sobre os alunos, entre outros.

No Brasil, pesquisas mostraram que, além do nível socioeconômico e da formação dos pais, outras categorias influenciam o desempenho dos alunos: organização e gestão da escola, nesse caso a forma de liderança do diretor (SOARES; ALVES, 2003); clima acadêmico, variadas características escolares que estão associadas à ênfase acadêmica da escola e ao foco no ensino e na aprendizagem (MACHADO SOARES, 2004); formação e salário docente (ALBERNAZ; FERREIRA; FRANCO, 2002); ênfase pedagógica, em matemática, por exemplo, resolução de problemas genuínos e contextualizados (FRANCO; SZTAJN; ORTIGÃO, 2007) e métodos ativos de ensino (SOARES; MAMBRINI; PEREIRA; ALVES, 2001); e infraestrutura (IE), atrelada aos recursos escolares, equipamentos e conservação, incluindo o prédio escolar (SOARES; MAMBRINI; PEREIRA; ALVES, 2001; LEE; FRANCO; ALBERNAZ, 2004).

Em relação à infraestrutura, Soares-Neto et al. (2013) criaram uma escala de quatro níveis com o intuito de medi-la nas escolas brasileiras. Nesse estudo, os pesquisadores revelaram que no nível mais elementar da escala estavam quase $45 \%$ (86.739) dos estabelecimentos de ensino, nesse caso, aqueles que possuíam somente aspectos elementares para o funcionamento (água, sanitário, energia, esgoto e cozinha). No nível básico, incluindo os itens presentes no nível anterior, em geral, as escolas (40\%-78.047) tinham sala de diretoria e equipamentos como TV, DVD, computadores e impressora.

O estudo mostrou também que no plano Adequado existiam 14,9\% (29.026) das unidades de ensino e elas possuíam sala de professores, biblioteca, laboratório de informática, sanitário para Educação Infantil, quadra esportiva, parque infantil, copiadora 
e acesso à internet. Os autores agruparam no nível avançado as escolas $(0,6 \%-1.120)$ que apresentaram uma IE próxima do ideal, aquelas que tinham laboratório de ciências e dependências adequadas para assistir aos jovens com necessidades especiais.

Esses pesquisadores demonstraram que quase $85 \%$ das escolas estavam centralizadas no nível elementar ou básico, revelando a dura realidade brasileira em relação à infraestrutura. $\mathrm{O}$ maior número de escolas estava localizado na esfera elementar e nas regiões Norte (71\%) e Nordeste (65,1\%). Já na região Sudeste, 22,7\% estavam no nível elementar, $57 \%$ no básico, $19,8 \%$ no adequado, e $0,5 \%$ no avançado. Nesse sentido, os melhores resultados ficaram com as unidades federais de ensino, com $62,5 \%$ nos níveis adequado e avançado. Nos estabelecimentos de ensino estaduais, 51,3\% situavam-se na categoria Básica, e nos municipais, 61,8\% na categoria Elementar.

Em outros estudos, pesquisadores constataram resultados positivos para o efeito das condições de funcionamento de laboratórios e espaços adicionais para atividades pedagógicas (ESPÓSITO; DAVIS; NUNES, 2000). Barbosa e Fernandes (2001), ampliando a compreensão sobre o fenômeno, revelaram que em qualquer uma das cinco regiões brasileiras, a IE (condições físicas e o ambiente escolar) influenciava positivamente o desempenho dos alunos. Por outro lado, e corroborando os estudos anteriores, estudiosos mostraram que a falta de recursos financeiros e pedagógicos afetava negativamente a eficácia da escola (ALBERNAZ; FERREIRA; FRANCO, 2002).

Pesquisas mais recentes indicaram também que a presença da infraestrutura adequada faz diferença em relação à aprendizagem dos alunos (SOARES, 2004; FRANCO; SZTAJN; ORTIGÃO, 2007). Soares, Razo e Fariñas (2006) explicaram parte dos baixos resultados da educação na área rural por meio da infraestrutura. Lee, Franco e Albernaz (2004) realizaram um estudo que apontou que a IE tem impacto positivo no desempenho de leitura dos jovens que participaram do Programa Internacional de Avaliação de Estudantes (Pisa) (2000).

Sintetizando, o desempenho do aluno está associado às características da escola, fatores que induzem à eficácia escolar. No entanto, a maior parte desse rendimento é determinado pelo NSE e pela formação dos pais. Entre os fatores escolares que influenciam positivamente o rendimento do jovem está a infraestrutura, que no Brasil se apresenta de forma empobrecida. Nesse caso, aproximadamente metade nas escolas brasileiras estava no nível mais elementar, a grande maioria situada nas regiões Norte e Nordeste, possuindo apenas aspectos básicos para o funcionamento. 


\section{A REGIÃO DO GRANDE ABC PAULISTA}

$\mathrm{Na}$ região do Grande $\mathrm{ABC}$, as cidades de Santo André, São Bernardo do Campo, São Caetano do Sul, Diadema, Mauá, Ribeirão Pires e Rio Grande da Serra compõem uma área de $635 \mathrm{~km}^{2}$, com uma população de mais de 2,5 milhões de residentes (IBGE, 2010). Uma das regiões mais ricas do Brasil, com um Produto Interno Bruto (PIB) industrial de, aproximadamente, R\$ 27 bilhões.

A Tabela 1, mostra o Índice de Desenvolvimento Humano Municipal (IDH-M) das cidades que participaram do estudo:

Tabela 1 - IDH-M dos municípios - 2010

\begin{tabular}{ll}
\hline Município & IDHM 2010 \\
\hline Santo André & 0,815 \\
São Bernardo do Campo & 0,805 \\
São Caetano do Sul & 0,862 \\
\hline
\end{tabular}

Fonte: adaptada do Atlas de Desenvolvimento Humano.

Trata-se de municípios com alto IDH-M entre as cidades brasileiras. Nesse contexto, São Caetano do Sul apresenta o maior índice do Brasil. Mas São Bernardo do Campo e Santo André também apresentam bons indicadores. A Tabela 2 mostra os municípios investigados e suas características demográficas:

Tabela 2 - Características demográficas - 2011

\begin{tabular}{lllll}
\hline Cidade & $\begin{array}{l}\text { População } \\
2013\end{array}$ & $\begin{array}{l}\text { Área da unidade } \\
\text { territorial } \mathrm{Km}^{2}\end{array}$ & $\begin{array}{l}\text { PIB (milhões } \\
\text { de R\$) }\end{array}$ & $\begin{array}{l}\text { Posição } \\
\text { do PIB }\end{array}$ \\
\hline Santo André & 704.942 & 175,781 & 17.664 .718 & $33^{\mathrm{a}}$ \\
São Bernardo do Campo & 805.895 & 409,478 & 36.337 .338 & $14^{\mathrm{a}}$ \\
São Caetano do Sul & 156.362 & 15,33 & 11.762 .744 & $48^{\mathrm{a}}$ \\
\hline
\end{tabular}

Fonte: adaptada de IBGE (2011).

Os três municípios investigados apresentaram infraestrutura avançada de acordo com o estudo de Soares-Neto et al. (2013), que criaram uma escala e mediram a infraestrutura das escolas brasileiras. Tal situação indica que essas escolas possuíam uma IE mais próxima do ideal com a presença de laboratório de ciências e dependências adequadas para atender a estudantes com necessidades especiais.

$\mathrm{Na}$ região do Grande $\mathrm{ABC}$, a maioria dos diretores que estavam atuando nas escolas de Ensino Fundamental era formada em Pedagogia, cursos de nível superior e, em geral, possuía algum tipo de pós-graduação. Em relação aos professores, 
havia no Brasil 2.148.023 na educação básica. Destes, 1.409.991 estavam inseridos no Ensino Fundamental (CENSO ESCOLAR, 2013). No Grande ABC existiam 198 escolas de Ensino Fundamental municipais e 143 nas três cidades investigadas. A região apresentava 160.680 matrículas no total da esfera municipal e 70.457 matrículas nos três municípios estudados (OBSERVATÓRIO DA EDUCAÇÃO DO GRANDE ABC, 2015).

Das três cidades investigadas, Santo André conta com escolas de Ensino Fundamental I (EFI), municipais e estaduais. No Município, participaram do IDEB, em 2013, 94\% das escolas. ${ }^{1}$ Destas, $50 \%$ conseguiram alcançar a meta municipal $(5,8)$ e, aproximadamente $50 \%$, a meta individual. Nesse sentido, quase $55 \%$ das unidades de ensino já atingiram a meta para o Brasil $(5,7)$ de 2021. Ressalta-se que o IDEB da cidade mostra evolução constante (4,9 em 2007 e 5,6 em 2013).

O Município de São Bernardo do Campo tem o Ensino Fundamental I inteiramente municipal. Participaram, em 2013, do IDEB, 92\% das escolas. A meta municipal $(5,9)$ foi atingida por, aproximadamente, $57 \%$ delas, e a meta individual, por quase $70 \%$ das unidades escolares. Nesse contexto, a meta para o Brasil $(5,7)$ de 2021 já foi alcançada por quase $75 \%$ das escolas. O EFI apresenta evolução constante, partindo da média 5,1 em 2007, e alcançando a nota 6,0 em 2013.

Na Cidade de São Caetano do Sul, no Ensino Fundamental I, todas as escolas pertenciam ao Município, visto que 17 delas participaram do IDEB em 2013. Assim, a meta municipal $(6,4)$ foi alcançada por quase $80 \%$ das escolas, e a individual, por aproximadamente $70 \%$. Todas as unidades de ensino já atingiram a meta para o Brasil $(5,7)$ de 2021. O EFI teve evolução gradual e constante, saindo de uma média de 5,9, em 2009, para uma nota de 6,6, em 2013, caracterizando-se no maior crescimento.

\section{METODOLOGIA}

Com este estudo, parte de um projeto de pesquisa mais amplo do Observatório da Educação do Grande ABC paulista, teve-se o objetivo de investigar e analisar, nas escolas municipais de Ensino Fundamental I da região do Grande ABC, como ocorre a interface entre a biblioteca e as possibilidades de aprendizagem dos alunos. Ou seja, como acontece a ligação física, organizacional e lógica entre os alunos e esse espaço, já que eles não estão conectados diretamente.

Como abordagem metodológica optou-se pela estratégia de estudo de caso, analisando, nesse processo, múltiplos casos simultaneamente (YIN, 1993). Nesse tipo 
de estudo pode-se partir de alguns pressupostos, orientando a coleta inicial de dados, mas, ao mesmo tempo, é preciso focar em outros elementos que surgem ao longo da pesquisa. Tais estratégias visam à descoberta e à compreensão do fenômeno que estão inseridas nos dados e em razão deles mesmos.

No estudo de caso, trata-se da interpretação de um contexto em que vários pontos de vista estão presentes. Em tal interpretação utiliza-se com frequência a estratégia de triangulação, recorrendo para isso a uma variedade de dados coletados em diferentes momentos e em múltiplas situações que podem ser provenientes de diferentes informantes. Usa-se também a triangulação de métodos ou de investigadores para garantir a qualidade dos resultados. Esse tipo de pesquisa procura retratar um fenômeno, revelando a multiplicidade de dimensões presentes, focalizando o todo sem perder de vista os detalhes, as situações específicas que permitem compreender o contexto.

A característica mais determinante do estudo de caso é sua ênfase na singularidade. Tal situação implica a análise do fenômeno de forma particular e única, ou seja, nesse contexto, trata-se de uma representação singular da realidade que é multidimensional e historicamente situada (ANDRÉ, 1984).

No ano 2012 foram selecionadas, inicialmente, 30 escolas municipais de EFI de vários munícipios da região do Grande $\mathrm{ABC}$ paulista (região metropolitana do Estado de São Paulo), a partir do Censo Escolar em que estão disponíveis informações sobre a qualidade do aprendizado de cada escola, município e estado brasileiro. Desses estabelecimentos de ensino, no entanto, somente 14, dos Municípios de Santo André, São Bernardo do Campo e São Caetano do Sul, concordaram em participar do estudo.

O critério de seleção de tais unidades escolares baseou-se na questão de a escola ter biblioteca e ter uma proporção de, pelo menos, 70\% de alunos, quintos anos, com aprendizado adequado na competência de leitura e interpretação de textos na Prova Brasil, disciplina de Português, no ano 2011. Essa estratégia de selecionar as escolas propositadamente, denominada por Patton (1990) de purposeful sampling, refere-se à ideia de obter informações mais precisas e diretas, o que não poderia ser conseguido com outra forma de seleção. A Tabela 3 mostra a descrição das escolas: 
Tabela 3 - descrição da escolas e nível de proficiência - 2011

\begin{tabular}{lll}
\hline Cidade & Escola & Alunos no nível adequado (\%) \\
\hline \multirow{3}{*}{ Santo André } & SA-01 & 71 \\
& SA-02 & 70 \\
SA-03 & 70 \\
São Bernardo do Campo & SBC-01 & 81 \\
& SBC-02 & 74 \\
& SBC-03 & 73 \\
& SBC-04 & 72 \\
& SBC-05 & 71 \\
São Caetano do Sul & SCS-01 & 87 \\
& SCS-02 & 87 \\
& SCS-03 & 86 \\
& SCS-04 & 85 \\
& SCS-05 & 80 \\
& SCS-06 & 72 \\
\hline
\end{tabular}

Fonte: o autor.

Os dados foram coletados por meio de entrevistas semiestruturadas com 14 diretores das escolas. As informações obtidas incidiram sobre o perfil do participante (sexo, idade, formação inicial e em nível de pós-graduação, experiência em gestão escolar) e sobre as ações educativas e projetos pedagógicos criados pelos professores e pela escola, utilizando a biblioteca para desenvolver a capacidade leitora dos jovens.

Em relação à categoria "b”, foram catalogados: o número de projetos realizados pela escola; o tipo, ou seja, se o programa era obrigatório ou livre para o aluno; a descrição e o objetivo; o local em que ele acontecia; e a periodicidade do programa. No mesmo sentido, foram agrupadas informações sobre as estratégias das escolas para lidar com a atualização dos acervos das bibliotecas.

Os dados foram analisados em concomitância com a coleta, o que possibilitou a investigação de novas questões as quais, eventualmente, surgiam. A análise inicial foi baseada na segmentação das informações fornecidas pelos diretores nas entrevistas e, para tal, foi utilizada uma investigação sobre os temas. Posteriormente, os dados foram filtrados com a utilização de códigos e descritores em uma codificação aberta e axial, propiciando reduzir, converter e agrupar as regularidades, similaridades e diferenças. Ideias, percepções e modos de compressão da realidade apresentados pelos diretores foram catalogados e analisados. Esse procedimento originou as categorias e subcategorias do estudo. Nesse tipo de análise de dados, de base qualitativa, a 
abordagem utilizada associa-se à teoria fundamentada (STRAUSS; CORBIN, 1990). Nesse enfoque, a teoria subjetiva construída pelo pesquisador é desenvolvida indutivamente a partir dos dados coletados.

\section{RESULTADOS}

Neste estudo, o perfil dos participantes, diretores de escolas municipais de Ensino Fundamental I, revelou que quase $83 \%$ dos profissionais eram do sexo feminino com a média de idade de, aproximadamente, 43 anos. Todos aqueles que participaram eram formados em Pedagogia, com algum tipo de pós-graduação e com um pouco mais de 12 anos de experiência na direção de escola. Trata-se, então, de uma demanda específica de gestores escolares de três municípios do Grande ABC.

As escolas investigadas utilizavam diferentes projetos pedagógicos, organizados pelos professores e pela gestão escolar, para realizar a interface entre o espaço biblioteca e a aprendizagem dos alunos. Nesse sentido, mais de 30 foram identificados e agrupados nas cinco categorias previamente elaboradas: número de projetos realizados pelas escolas; tipo; descrição do programa; local de desenvolvimento e periodicidade. Esse agrupamento foi possível, pois na análise dos dados poucas diferenças significativas foram observadas entre as escolas dos três municípios estudados, indicando que muitas das estratégias utilizadas eram comuns a todas as unidades de ensino.

Nas escolas, as ações educativas e os projetos pedagógicos tinham objetivos bem definidos. Procurava-se desenvolver a leitura no âmbito da biblioteca e da sala de aula e utilizá-la como uma das estratégias mais importantes no processo de aprendizagem para enriquecer os conteúdos ministrados na sala de aula e ampliar o tempo de aprendizagem, utilizando a estratégia de leitura como dever de casa. Ao mesmo tempo, buscava-se melhorar o desempenho do jovem em leitura; ampliar e desenvolver as competências leitoras relacionadas ao falar, escrever, ler, dialogar e discutir; aumentar os conhecimentos dos jovens, usando a abordagem transversal em que o estudante realiza leitura sobre, por exemplo, o meio ambiente ou a saúde e usar a leitura e a interpretação para desenvolver o senso crítico e a cidadania do jovem.

De fato, observa-se nos objetivos descritos e desenvolvidos que as escolas valorizavam a biblioteca como ambiente de aprendizagem para o estudante melhorar seu desempenho e consideravam tal local como um espaço formativo, consolidando a ideia de que a biblioteca apresenta influência positiva no desempenho dos jovens (CASASSUS, 2002; BIONDI; FELÍCIO, 2007; FELÍCIO, 2008). 
As escolas da Cidade de São Caetano do Sul desenvolviam o maior número de projetos. As seis unidades pesquisadas utilizavam 25 projetos com os alunos, o que demonstra a valorização da biblioteca e da leitura para a formação do jovem. De fato, o depoimento de um diretor ilustra a situação este afirma que "[...] a biblioteca como espaço de formação é parte integrante do nosso projeto pedagógico para desenvolver a competência leitora do aluno e seu gosto pela leitura. Muitos projetos são realizados lá pelos professores.” (Diretor, SCS-04, informação verbal).

Nas cinco escolas da Cidade de São Bernardo do Campo eram desenvolvidos 15 projetos, e nas três de Santo André, 12. Nesses estabelecimentos de ensino, a biblioteca era muito valorizada como espaço para a aprendizagem e para a leitura e, ao mesmo tempo, ela era considerada um local de formação: “[...] escola que tem bons resultados mantém o foco na leitura, sempre, sempre, usando a biblioteca." (Diretor, SA-02, informação verbal). Há um interesse nítido dessas escolas em fomentar o uso desse espaço para a formação do aluno. O Quadro 1 mostra uma síntese dos projetos desenvolvidos:

Quadro 1 - Projetos desenvolvidos - 2012

\begin{tabular}{|l|l|l|l|l|l|l|l|l|l|}
\hline Projetos & $\begin{array}{l}\text { N. } \\
\text { esc. }\end{array}$ & Tipo & Local & Projetos & $\begin{array}{l}\text { N. } \\
\text { esc. }\end{array}$ & Tipo & Local & $\begin{array}{l}\text { Proje- } \\
\text { tos de } \\
\text { incentivo à } \\
\text { leitura }\end{array}$ & $\begin{array}{l}\text { N. } \\
\text { esc. }\end{array}$ \\
\hline $\begin{array}{l}\text { Biblioteca } \\
\text { circulante }\end{array}$ & 14 & O & C & $\begin{array}{l}\text { Leitura seria- } \\
\text { da feita pelo } \\
\text { professor }\end{array}$ & 9 & O & SL; B & $\begin{array}{l}\text { Festa do } \\
\text { livro }\end{array}$ & 14 \\
\hline $\begin{array}{l}\text { Leitura } \\
\text { comparti- } \\
\text { lhada }\end{array}$ & 10 & O & B; SL & $\begin{array}{l}\text { Indicação } \\
\text { de livros por } \\
\text { faixa etária }\end{array}$ & 14 & O & SL; B & $\begin{array}{l}\text { Bienal do } \\
\text { livro }\end{array}$ & 6 \\
\hline $\begin{array}{l}\text { Roda de } \\
\text { leitura }\end{array}$ & 13 & O & B; SL & $\begin{array}{l}\text { Adoção de } \\
\text { livros paradi- } \\
\text { dáticos }\end{array}$ & 14 & O & SL & $\begin{array}{l}\text { Sorteio de } \\
\text { livros entre } \\
\text { os alunos }\end{array}$ & 5 \\
\hline $\begin{array}{l}\text { Mala de } \\
\text { leitura }\end{array}$ & 8 & O & C & $\begin{array}{l}\text { Incentivo } \\
\text { à leitura de } \\
\text { poesias }\end{array}$ & 6 & L & B; SL & $\begin{array}{l}\text { Feira de } \\
\text { troca de } \\
\text { livros }\end{array}$ & 11 \\
\hline $\begin{array}{l}\text { Biblioteca } \\
\text { viva }\end{array}$ & 11 & O & B; SL & $\begin{array}{l}\text { Leitura } \\
\text { diária no } \\
\text { final de cada } \\
\text { período }\end{array}$ & 6 & O & SL & $\begin{array}{l}\text { Escambo } \\
\text { com toda } \\
\text { escola (gi- } \\
\text { bis, livros, } \\
\text { textos) }\end{array}$ & 6 \\
\hline $\begin{array}{l}\text { Caixa de } \\
\text { leitura }\end{array}$ & 6 & O & C & $\begin{array}{l}\text { Leitura de } \\
\text { temas atuais } \\
\text { (Copa do } \\
\text { Mundo }\end{array}$ & 5 & O & SL; B & $\begin{array}{l}\text { Sarau } \\
\text { Sara }\end{array}$ & 4 \\
\hline
\end{tabular}




\begin{tabular}{|l|l|l|l|l|l|l|l|l|l|}
\hline $\begin{array}{l}\text { Sessão } \\
\text { paralela } \\
\text { (ou simul- } \\
\text { tânea) de } \\
\text { leitura }\end{array}$ & 9 & O & B; SL & $\begin{array}{l}\text { Primeira aula } \\
\text { na biblioteca } \\
\text { inserida } \\
\text { na rotina } \\
\text { escolar }\end{array}$ & 6 & O & B & $\begin{array}{l}\text { Clube dos } \\
\text { pequenos } \\
\text { leitores }\end{array}$ & 5 \\
\hline $\begin{array}{l}\text { Varal de } \\
\text { leitura }\end{array}$ & 10 & L & SL & $\begin{array}{l}\text { Carrinhos } \\
\text { com livros } \\
\text { paradidáticos } \\
\text { nas salas }\end{array}$ & 8 & L & B; SL & $\begin{array}{l}\text { Estantes } \\
\text { de leitura } \\
\text { nas salas de } \\
\text { aula }\end{array}$ & 14 \\
\hline $\begin{array}{l}\text { Mural de } \\
\text { indicações } \\
\text { literárias }\end{array}$ & 8 & L & B & $\begin{array}{l}\text { Leitor do } \\
\text { mês }\end{array}$ & 6 & O & B & $\begin{array}{l}\text { Tarde de } \\
\text { autógrafos }\end{array}$ & 6 \\
\hline $\begin{array}{l}\text { Momento } \\
\text { literário }\end{array}$ & 7 & O & B & $\begin{array}{l}\text { Sinal musi- } \\
\text { cal com a le- } \\
\text { tra da música } \\
\text { exposta no } \\
\text { mural }\end{array}$ & 1 & L & OE & $\begin{array}{l}\text { Atividades } \\
\text { comemora- } \\
\text { tivas com } \\
\text { leitura. }\end{array}$ & 7 \\
\hline $\begin{array}{l}\text { Oficina de } \\
\text { leitura }\end{array}$ & 10 & O & B & $\begin{array}{l}\text { Oficina em } \\
\text { parceria com } \\
\text { a Secretaria } \\
\text { de Cultura }\end{array}$ & 3 & L & OE & $\begin{array}{l}\text { Oativas, in- } \\
\text { centivando } \\
\text { à leitura: } \\
\text { Sem. } \\
\text { Monteiro } \\
\text { Lobato }\end{array}$ & 6 \\
\hline
\end{tabular}

Fonte: $o$ autor.

Nota: $\mathrm{O}=$ obrigatórios; $\mathrm{L}=$ livre; $\mathrm{B}=$ biblioteca; $\mathrm{SL}=$ sala de aula; Outro espaço escolar $=\mathrm{OE}$; $\mathrm{C}=$ casa. $\mathrm{N}$. esc. $=$ número de escolas.

A maioria dos projetos desenvolvidos pelas escolas tinha caráter obrigatório para os alunos, o que garantia a participação do estudante. O Programa Biblioteca circulante na cidade de São Caetano do Sul, por exemplo, caracterizava-se por um projeto em que cada aluno escolhia um livro, dos exemplares que eram previamente selecionados pela professora e estavam disponíveis na biblioteca ou daqueles que ficavam na sala de aula, e o levava para a leitura em casa. Nesse sentido, a criança contava com um tempo determinado para realizar o trabalho. Após esse período, o livro era trocado, forçando a leitura de mais de um exemplar ao longo de um trimestre. ${ }^{2}$

O Projeto Leitura compartilhada, com pequenas diferenças em algumas escolas, caracterizava-se pela leitura de capítulos de um livro selecionado pela professora. Tratava-se de uma atividade que acontecia na biblioteca ou na sala de aula, em que cada criança tinha um exemplar em mãos para acompanhar a leitura de um colega. No final, geralmente, ocorria uma discussão, e os alunos tinham a oportunidade de apresentar suas ideias sobre o tema. 
O Projeto Primeira aula no espaço da biblioteca estava inserido na rotina escolar e também tinha caráter obrigatório para os jovens. As escolas se organizavam de forma que a primeira aula do dia acontecia na biblioteca, um tipo de organização para favorecer a utilização do espaço e desenvolver o gosto pela leitura nos alunos. Geralmente, a escola organizava um rodízio para atender a todas as turmas. Nesse trabalho, os jovens tinham a possibilidade de conhecer e vivenciar esse espaço e realizar múltiplas leituras, diariamente.

Os projetos aconteciam, em geral, na biblioteca e na sala de aula (Quadro 1). Um exemplo era o Projeto "Biblioteca viva" que, dependendo da escola, tinha periodicidade diferente. Nesse Projeto, a escola dispunha de um pequeno acervo de livros da biblioteca e este circulava ou nesse espaço ou na sala de aula para que os alunos pudessem escolher um exemplar para a leitura. Quando a escolha era realizada, os jovens dispunham de um tempo atribuído pela professora para realizar a leitura e a análise da obra.

Os projetos tinham periodicidades diferentes. Alguns aconteciam no início do ano (leitura seriada, indicação de livros para a faixa etária), outros no final (feira do livro). No entanto, a maioria daqueles que eram obrigatórios ocorria ao longo do ano, uma tentativa deliberada de fomentar a leitura entre os jovens.

Um projeto muito utilizado pelas escolas de São Caetano era o denominado Sessão paralela ou simultânea de leitura. Tratava-se, nesse trabalho, de estabelecer um dia e horário na semana em que toda a escola realizaria um tipo de leitura com a utilização de diferentes linguagens (caracterização, música, encenação). Nesse dia, cada professor escolhia um livro e a forma de leitura deste para os alunos. Muitas vezes, a leitura era dramatizada pelos próprios jovens ou por pessoas convidadas pela direção da escola.

Alguns projetos tinham periodicidade anual: Varal de leitura, em que ficavam expostos, diariamente, durante os intervalos das aulas, gibis, revistas e jornais, com o objetivo de provocar o desejo de leitura nas crianças; Mural de indicação literárias, no qual alunos eram estimulados a indicar por escrito os livros que leram durante um período. Essas indicações e comentários permaneciam à disposição nos murais da escola, locais onde os estudantes tinham acesso, inclusive em horários vagos, como na espera do transporte escolar.

As escolas tinham vários projetos relacionados à ideia de incentivar os alunos para a leitura. A Festa do livro era uma comemoração realizada em algumas unidades escolares com o objetivo principal de incentivar a compra e a leitura de livros. Geralmente, nesses eventos, algumas editoras eram convidadas a expor uma grande 
variedade de títulos de diversos gêneros e para diferentes faixas etárias. Outra atividade, com o mesmo objetivo, era a tarde de autógrafos. Nessa proposta, geralmente, as escolas aproveitavam a feira do livro para convidar um autor para contar uma história e autografar os livros das crianças. Uma variação dessa proposta era a publicação de uma coletânea de textos trabalhados e escritos pelos próprios estudantes, para que estes, em uma data específica, pudessem autografar seus livros e oferecê-los à comunidade escolar.

Ainda com o mesmo objetivo, incentivar nos alunos o gosto pela leitura, algumas escolas realizavam o Projeto Identificação do leitor do mês. Nesse trabalho, a equipe gestora e a professora acompanhavam os empréstimos de livros que ocorriam durante o mês, o bimestre ou o trimestre pelos alunos e no final presenteavam com um livro aquele jovem que mais se interessou em usar a biblioteca, ou seja, na atividade de leitura. Isso permitia que os gestores monitorassem os alunos nessa habilidade. Como sinalizou uma diretora, quando "[...] o aluno lê pouco isto nos preocupa e aí temos de acompanhar mais de perto o menino e motivá-lo, sabe, e falar com ele, sabe, e até mesmo conversar com seus pais, se necessário. Acompanhar e acompanhar sua leitura." (Diretor, SCS-06, informação verbal).

Por fim, as escolas tinham ações bem definidas para atualizar ou melhorar o acervo de suas bibliotecas. Elas, em geral, utilizavam uma das seguintes estratégias:

a) solicitavam doações de livros, revistas e gibis velhos ou novos para as famílias e para a comunidade,

b) trocavam livros, gibis e mapas com outras escolas ao longo do ano;

c) promoviam festas e eventos para arrecadar fundos para comprar livros novos;

d) solicitavam para a Associação de Pais e Mestres (APM) a compra de alguns títulos;

e) realizavam parceria com pais ou empresas para o financiamento de compra de livros;

f) realizavam feira de livros com as editoras e solicitavam a doação de alguns exemplares para a escola.

Há um último fator importante revelado nas entrevistas. Em 10 das 14 escolas $(71 \%)$ que tinham um maior número de projetos e estratégias claras para lidar com a utilização da biblioteca e as possibilidades de aprendizagem dos alunos, os diretores tinham clareza da importância desse espaço na formação leitora do aluno, 
eram entusiasmados em relação ao trabalho e contagiavam seus professores, possuíam fundamentação teórica sobre o tema e planejavam as ações e os projetos pedagógicos.

Sintetizando, os resultados encontrados apontaram que mais de 30 projetos de leitura foram identificados, atuando na interface entre a biblioteca e o desenvolvimento da competência leitora dos alunos. Eles possuíam vários objetivos, entre eles, motivar os jovens à leitura. São Caetano era a cidade que possuía o maior número de iniciativas pedagógicas. A maioria dos projetos desenvolvidos tinha caráter obrigatório para os alunos e periodicidade diferente (mensal, bimestral ou anual), e as escolas possuíam ações bem delimitadas para atualizar ou melhorar o acervo de suas bibliotecas. Nesse processo, a participação do diretor era fundamental, desde o planejamento até a motivação dos professores.

\section{DISCUSSÃO DOS RESULTADOS}

Este estudo contribuiu, em geral, para ampliar o entendimento sobre o tema infraestrutura realizado por vários pesquisadores (CASTRO; FLETCHER, 1986; BARBOSA; FERNANDES, 2001; FRANCO; BONAMINO, 2005; SOARES; RAZO; FARIÑAS, 2006; SÁTYRO; SOARES, 2007; SOARES-NETO et al., 2013). Ao mesmo tempo, ampliou também a compreensão sobre o efeito biblioteca, trazendo pistas mais detalhadas de como ele ocorre, considerando que a grande maioria dos estudos em relação ao tema identifica o efeito por meio de análises quantitativas, mas não mostra como o fenômeno acontece na escola (CASASSUS, 2002; BIONDI; FELÍCIO, 2007; FELÍCIO, 2008). Sem esse tipo de análise pormenorizada, qualitativa, não se pode compreender o fenômeno em sua totalidade e realizar indicações para a organização do trabalho escolar.

Destaca-se que a utilização da biblioteca, vinculada às possibilidades de aprendizagem dos alunos, é tratada como assunto sério pela maioria dos diretores dentro do planejamento anual de ensino. Nesse contexto, eles conheciam, entre outras coisas, o potencial desse local para a formação leitora do aluno e, ao mesmo tempo, idealizavam iniciativas e projetos pedagógicos, liderando seus professores com entusiasmo. Existe, portanto, um componente forte desse trabalho atrelado à gestão escolar e aos mecanismos de liderança do diretor. De fato, a gestão escolar tem sua atuação na organização, mobilização e articulação dos processos materiais e humanos da escola a fim de torná-la mais eficaz. Sua ação está associada, entre outras coisas, à organização e à gestão de pessoas, ao gerenciamento administrativo e pedagógico e aos resultados dos alunos (LÜCK, 2009, p. 24). 
Neste estudo foram mostrados pontos fundamentais dessas escolas. Elas possuíam objetivos claros, valorizavam o espaço da biblioteca e tinham estratégias bem definidas para a atualização dos acervos. Os objetivos, em geral similares, estavam relacionados ao desenvolvimento da leitura no âmbito da biblioteca para ampliar o senso crítico e a cidadania do aluno, à utilização da leitura como estratégia de aprendizagem para enriquecer os conteúdos, e à ampliação do tempo de aprendizagem, entre outros. Destaca-se que em todas as unidades de ensino, tanto para os professores quanto para a equipe escolar, a biblioteca e a leitura eram muito valorizadas para a formação geral do aluno. E, por fim, esses estabelecimentos de ensino possuíam preocupações constantes quanto à atualização dos acervos de suas bibliotecas, utilizando, entre outras estratégias, a solicitação de auxílio das famílias, as trocas de materiais com outras escolas, a promoção de festas e parcerias com pais ou empresas e a realização de feiras de livros. De fato, quando se analisaram os resultados dessas escolas na Prova Brasil de 2011, em termos da porcentagem de alunos que aprenderam adequadamente as competências de leitura e a interpretação de texto, essas instituições apresentaram altos rendimentos (INSTITUTO NACIONAL DE ESTUDOS E PESQUISAS EDUCACIONAIS ANÍSIO TEIXEIRA, 2011).

Nesse contexto, duas outras diferenciações vieram à tona. A primeira indica que todas as escolas possuíam vários tipos de projetos, induzindo os alunos ao uso da biblioteca e à leitura, sinalizando que essas iniciativas estavam presentes com o intuito de melhorar a capacidade leitora dos jovens. Embora não se possa criar nenhum tipo de correlação entre o número de projetos e os resultados dos estudantes, a cidade de São Caetano do Sul foi aquela que apresentou a maior quantidade dessas inciativas e o melhor rendimento dos alunos. Esse Município já exibia os melhores rendimentos em outras avaliações realizadas sobre a infraestrutura da cidade (GARCIA, 2014), sobre a infraestrutura da região do grande ABC (GARCIA et al., 2014) e sobre o desempenho dos alunos no Indice de Desenvolvimento da Educação Básica (IDEB) (GARCIA et al., 2015). A segunda sinaliza que, apesar de ter periodicidade diferente, a maioria dos projetos dos estabelecimentos de ensino tinha caráter obrigatório para os alunos, induzindo-os à leitura. Um número menor possuía orientação livre.

Além dos três pontos indicados e das duas diferenciações já destacadas, outro ponto merece destaque. Ressalta-se que muitos projetos aconteciam na sala de aula, revelando que o fato de a escola possuir poucos livros, ou apenas um pequeno acervo, não se constituía em um fator impeditivo para o desenvolvimento da leitura. Tal situação traduz-se em uma relevante indicação para os gestores escolares e para os professores, em geral, e para as alfabetizadoras, em particular. 


\section{CONSIDERAÇÕES FINAIS}

Os resultados deste estudo permitiram compreender como algumas escolas municipais de Ensino Fundamental I, de três municípios da região do ABC paulista, realizavam, utilizando iniciativas educativas e projetos pedagógicos, a interface entre a biblioteca e as possibilidades de aprendizagem dos alunos. Considerando a região em que o estudo foi realizado, com alto IDH-M e condições de vida bastante acima da média brasileira, pode-se inferir que os resultados encontrados refletem uma realidade diferente, mas que pode auxiliar os gestores na reflexão e na discussão sobre a organização das escolas, em termos da aproximação da biblioteca (leitura) à realidade dos alunos. Tal situação pode favorecer, paralelamente, a descoberta de possíveis alternativas para a organização de ações e de projetos de aprendizagem e de leitura.

Considerando que o desempenho do aluno no Brasil é tributário da infraestrutura, conhecer o efeito biblioteca em detalhes pode impulsioná-lo, potencializando a aprendizagem em leitura e interpretação de texto. Compreender a organização das ações educativas e dos projetos pedagógicos e o sentido destes para as escolas contribui trazendo indicações aos diretores no intuito de auxiliá-los a melhorar o desempenho dos alunos em leitura. Paralelamente, essa contribuição pode ser utilizada para a discussão nos cursos de formação inicial e continuada de gestores escolares e fomentar o debate entre os especialistas das secretarias de educação de outros municípios.

Uma das principais contribuições deste estudo foi ampliar a compreensão do efeito biblioteca na aprendizagem do aluno (conhecer um pouco mais sobre como ele ocorre na escola) e oferecer, paralelamente, aos pesquisadores e gestores escolares uma base teórica mais sólida para a compreensão do fenômeno. Seria interessante a replicação deste estudo em outras regiões brasileiras, pois isso possibilitaria a ampliação desse entendimento, beneficiando as escolas e o desenvolvimento da capacidade leitora das crianças.

Notas explicativas:

${ }^{1}$ Os motivos da não participação de uma escola podem estar associados ao número insuficiente (abaixo de 20) de alunos que realizam a Prova Brasil daquele ano para que os resultados sejam divulgados, ou as unidades de ensino podem não possuir turmas de quinto ano no ano da avaliação.

${ }^{2}$ Nessa cidade a organização do trabalho escolar, docente e curricular era trimestral. 


\section{REFERÊNCIAS}

ALBERNAZ, A.; FERREIRA, F. H. G.; FRANCO, C. Qualidade e equidade na educação fundamental brasileira. Texto para Discussão n. 455. Rio de Janeiro: PUC-Rio, 2002.

ANDRÉ, M. E. D. A. Estudo de caso: seu potencial em educação. Caderno de Pesquisa, n.54, p.51-54, maio, 1984. Disponível em: <http://publicacoes.fcc.org.br/ojs/ index.php/cp/article/view/1427/1425> Acesso em: 23 maio 2014.

BARBOSA, M. E. F.; FERNANDES C. A escola brasileira faz diferença? Uma investigação dos efeitos da escola na proficiência em matemática dos alunos da $4^{\mathrm{a}}$ série. In: FRANCO, C. (Org.). Avaliação, ciclos e promoção na educação. Porto Alegre: Artmed, 2001.

BIONDI, R. L.; FELÍCIO, F. Atributos Escolares e o Desempenho dos Estudantes: uma Análise em Painel dos Dados do SAEB. Brasília, DF: Inep, 2007.

CASASSUS, J. A escola e a desigualdade. Brasília, DF: Plano, 2002.

CASTRO, C. M.; FLETCHER, P. A escola que os brasileiros frequentaram em 1985. Rio de Janeiro: Ipea: Iplan, 1986.

CENTRE DE RECHERCHE DE L'EDUCATION SPECIALISEE ET DE L'ADAPTATION SCOLAIRE. Le handicap socioculturel en question. Paris: ESF, 1978.

CÉSAR, C.; SOARES, J. Desigualdades acadêmicas induzidas pelo contexto escolar. Revista Brasileira de Estudos de População, v. 18, n. 1/2, p. 97-110, 2001.

COLEMAN, J. S. Equality of educational opportunity. Washington: US Government Printing Office, 1966.

CORBIN, J.; STRAUSS, A. Basics of qualitative research: techniques and procedures for developing grounded theory. 2. ed. London: Sage Publications, 1998.

CRAHAY, M.; BAYE, A. Existem escolas justas e eficazes? Cad. Pesqui., São Paulo, v. 43, n. 150, 2013. Disponível em: <http://www.scielo.br/scielo. php?script=sci_arttext\&pid=S0100-15742013000300007\&lng=pt\&nrm=iso $>$. Acesso em: 27 jun. 2014.

DOUGLAS, J. W. B.; ROSS, J. M.; SIMPSON, H. R. All our future. London: P. Davies, 1968. 
ESPÓSITO, Y. L.; DAVIS, C.; NUNES, M. M. R. Sistema de Avaliação do Rendimento Escolar - O modelo adotado pelo Estado de São Paulo. Revista Brasileira de Educação, n. 13, p. 25-53, 2000.

FELÍCIO, F. Fatores associados ao sucesso escolar: levantamento, classificação e análise de estudos realizados no Brasil. São Paulo: Fundação Itaú Social, 2008.

FELÍCIO, F.; FERNANDES, R. O Efeito da Qualidade da Escola sobre o Desempenho Escolar: uma avaliação do Ensino Fundamental no Estado de São Paulo. ENCONTRO NACIONAL DE ECONOMIA, 33., 2005, Natal. Anais... Natal, 2005.

FERRÃO, M. E.; BELTRÃO, K.; SANTOS, D. Políticas de não repetência e qualidade da educação: evidências obtidas a partir da modelagem dos dados da $4^{\mathrm{a}}$ série do SAEB-99. Estudos em Avaliação Educacional, n. 26, 2002.

FLETCHER, P. À procura do ensino eficaz: Relatório de pesquisa. Brasília, DF: PNUD: MEC: SAEB, 1997.

FRANCO, C.; BONAMINO, A. A pesquisa sobre características de escolas eficazes no Brasil: breve revisão dos principais achados e alguns problemas em aberto. Revista Educação On-line, Rio de Janeiro: PUC-Rio, n. 1, 2005.

FRANCO, C.; SZTAJN, P.; ORTIGÃO, M. I. Mathematics teachers, reform, and equity: results from the Brazilian National Assessment. Journal for Research in Mathematics Education, Reston, Virginia, v. 38, i. 4, p. 393-419, 2007.

GARCIA, P. S. et al. A Infraestrutura das Escolas de Ensino Fundamental da Região do Grande ABC Paulista. Revista Ibero-Americana de Estudos em Educação, v. 9, p. 614-631, 2014.

GARCIA, P. S. et al. Desempenho escolar: uma análise do IDEB das cidades da Região do Grande ABC. In: GARCIA, P. S.; PREARO, L. (Org.). Avaliação da educação escolar no Grande ABC Paulista: primeiras aproximações. 1. ed. São Paulo: Plêiade, 2015.

GARCIA, P. S. Um estudo de caso analisando a infraestrutura das escolas de ensino fundamental. Cadernos de Pesquisa: Pensamento Educacional, Curitiba, v. 9, p. 153-175, 2014.

IBGE. São Paulo > São Caetano do Sul > infográficos: evolução populacional e pirâmide etária. Censo Demográfico. 2010. Disponível em: $<$ http://www.cidades. ibge.gov.br/painel/populacao.php?lang=\& codmun=354880\&search=sao-paulo|sao-caetano-do-sul|infograficos:-evolucao-populacional-e-piramide-etaria $>$. Acesso em: 23 abr. 2013. 
INSTITUTO NACIONAL DE ESTUDOS E PESQUISAS EDUCACIONAIS ANÍSIO TEIXEIRA. Resultados da Prova Brasil de 2011. 2011. Disponível em: $<$ http://portal.inep.gov.br/basica-levantamentos-acessar>. Acesso em: 09 jul. 2014.

LEE, V. E.; BRYK, A. S.; SMITH, J. The Organization of Effective Secondary Schools. In: DARLING-HAMMOND, L. Review of Research in Education. Washington: American Educational Research Association, 1993.

LEE, V.; FRANCO, C.; ALBERNAZ, A. Quality and equality in Brazilian secondary schools: a multilevel cross-national school effects study. San Diego: Annual Meeting of the American Educational Research Association, 2004.

LÜCK, H. Dimensões de gestão escolar e suas competências. Curitiba: Positivo, 2009.

MACHADO SOARES, T. Influência do Professor e do Ambiente em Sala de Aula sobre a Proficiência Alcançada pelos Alunos Avaliados no Simave-2002. 2004. Disponível em: <http://www.fcc.org.br/pesquisa/publicacoes/eae/arquivos/1112/1112.pdf>. Acesso em: 09 jul. 2014.

MELLA, O. et al. (Org.). Qualitative study of schools with outstanding results in seven Latin American countries. Santiago: UNESCO: Latin American Laboratory for Assessment of the Quality of Education, 2002.

OBSERVATÓRIO DA EDUCAÇÃO DO GRANDE ABC. Dados do Caderno Educação. Diário do Grande ABC, 14 jun. 2015.

ORGANIZAÇÃO PARA A COOPERAÇÃO E DESENVOLVIMENTO ECONÔMICO. Résultats du Pisa 2009. Surmonter le milieu social: l'égalité des chances et l'équité du rendement de l'apprentissage, 2. Paris: OCDE, 2011.

PATTON, M. Q. Qualitative evaluation and research methods. 2nd ed. Newbury Park: Sage, 1990.

RACZYNSKI, D.; MUÑOZ, G. Reforma educacional Chilena: el difícil equilibrio entre la macro y micro-politica. REICE - Revista Electrónica Iberoamericana sobre Calid, Eficacia y Cambio em Educacional, v. 5, n. 3, 2007.

SAMMONS, P.; HILLMAN, J.; MORTIMORE, P. Key Characteristics of Effective Schools: A Review of School Effectiveness Research. London: Office for Standards in Education (OFSTED), 1995.

SÁTYRO, N.; SOARES, S. A infraestrutura das escolas brasileiras de ensino fundamental: um estudo com base nos censos escolares de 1997 a 2005 . Textos para Discussão n. 1267. Brasília, DF: IPEA, 2007. 
SAUVY, A.; GIRARD, A. Les diverses classes sociales devant l'enseignement. Population, 2. Reprisin INED (1970), Population et l'enseignement. Paris: PUF, 1965.

SOARES, J. F.; ALVES, M. T. Desigualdades Raciais no Sistema Brasileiro de Educação Básica. Educação e Pesquisa, São Paulo, v. 29, p. 147-165, 2003.

SOARES, J. F.; CÉSAR, C. C.; MAMBRINI, J. Determinantes de desempenho dos alunos do ensino básico brasileiro: evidências do SAEB de 1997. In: FRANCO, C. (Org.). Avaliação, ciclos e promoção na educação. Porto Alegre: Artmed, 2001.

SOARES, J. F. et al. Fatores associados ao desempenho em Língua portuguesa e matemática: evidência do SAEB - 2001. Minas Gerais: UFMG, 2001.

SOARES, J. F. Qualidade e eqüidade na educação básica brasileira: a evidência do SAEB-2001. Arquivos Analíticos de Políticas Educativas, v. 12, n. 38, 2004.

SOARES-NETO, J. J. et al. Uma escala para medir a infraestrutura escolar. Est. Aval. Educ., São Paulo, v. 24, n. 54, p. 78-99, 2013.

SOARES, S.; RAZO, R.; FARIÑAS, M. Perfil estatístico da educação rural: origem socioeconômica desfavorecida, insumos escolares deficientes e resultados inaceitáveis. In: BOF, A. M. (Org.). A educação no Brasil rural. Brasília, DF: Instituto Nacional de Estudos e Pesquisas Educacionais Anísio Teixeira, 2006.

STRAUSS, A.; CORBIN, J. Basics of qualitative research: techniques and procedures for developing grounded theory. 2. ed. London: Sage Publications, 1998.

YIN, R. K. Applications of case study research. Thousand Oaks: SAGE Publications, 1993.

Endereço para correspondência: Avenida Goiás, 3400, Barcelona, 09550-051, São Caetano do Sul, São Paulo, Brasil; garciaps@usp.br 